\begin{tabular}{c|c|c}
\hline \hline $\begin{array}{c}\text { Vol. 34(4):403-411 } \\
\text { http://dx.doi.org/10.4217/OPR.2012.34.4.403 }\end{array}$ & Ocean and Polar Research & December 2012 \\
\hline
\end{tabular}

Article

\title{
Seasonal Variation of Volume Transport through the Straits of the East/Japan Sea Viewed from the Island Rule
}

\author{
Young Ho Seung ${ }^{*}$, Soo-Yeon Han, and Eun-Pyo Lim \\ Department of Oceanography, College of Natural Science, Inha University \\ Incheon 402-751, Korea
}

\begin{abstract}
Among others, a question that has long been unanswered is why the seasonal variation of volume transport is larger in the Soya and Korea/Tsushima Straits than in the Tsugaru Strait. An attempt is made to answer this question in terms of the island rule with friction being taken into account. The problem is idealized as a simple model. The model results indicate that volume transport through a channel is determined not only by the circulation created around the adjacent island but also by those created around the neighboring islands farther away. The latter is due to the presence of bottom friction in the channels. The volume transports through the Korea/Tsushima, Tsugaru and Soya Straits estimated from the model using observed wind data show the general pattern of observed seasonality, although they contain large errors associated with the uncertain frictional parameter employed in the model. The model indicates that the observed seasonality arises essentially from the fact that wind stress curl changes its sign, from negative in the summer to positive in winter, following a large fluctuation of zero-stress curl latitude east of Hokkaido.
\end{abstract}

Key words : East/Japan Sea, volume transport, seasonal variation, island rule, bottom friction

\section{Introduction}

The Tsushima Current is a buoyant through-flow that enters the East/Japan Sea (hereafter, East Sea) through the Korea/Tsushima Strait and flows out to the North Pacific through the Tsugaru and Soya Straits (Fig. 1). The East Sea also communicates to the north with the Okhotsk Sea although the corresponding volume transport is known to be negligible. The waters carried by the Tsushima Current are believed to originate from both the Taiwan Warm Current (Fang et al. 1991; Katoh et al. 1996) and the Kuroshio (Lie and Cho 1994). There are some studies showing that the volume transport of the Tsushima Current is related with the sea level difference between the interior and exterior of the East Sea (Toba et al. 1982; Ohshima 1994; Tsujino et al. 2008). On larger spatial and time scales, however, it is linked to the wind-driven ocean circulation in the North Pacific. This idea was first

\footnotetext{
*Corresponding author. E-mail : seung@inha.ac.kr
}

explored by Minato and Kimura (1980). They considered a barotropic, linear dissipative, wind-driven ocean connected on the west to a shallow marginal sea through narrow inflow and outflow channels, and successfully demonstrated that the transport through the marginal sea is driven by a large-scale wind field. The resulting volume transport was greatly overestimated because of many simplifications. Among others, the most important cause of such discrepancy may be the neglect of large bottom friction in the inflow and outflow channels. In the same line, Nof (1993) considered the same problem as a geostrophic adjustment of buoyant Kuroshio water injecting through a narrow gap into the marginal sea filled with deep, heavier motionless water. Later, he also considered various other models applicable to the estimation of volume transport of the Tsushima Current (Nof 2000): one-and-half layer numerical model (Bleck and Smith 1990), Godfrey's island rule (Godfrey 1989), and Nof's (1993) $\beta$-controlled formula. All these models are non-linear except for the island rule and neglect bottom friction. They all give a transport of 


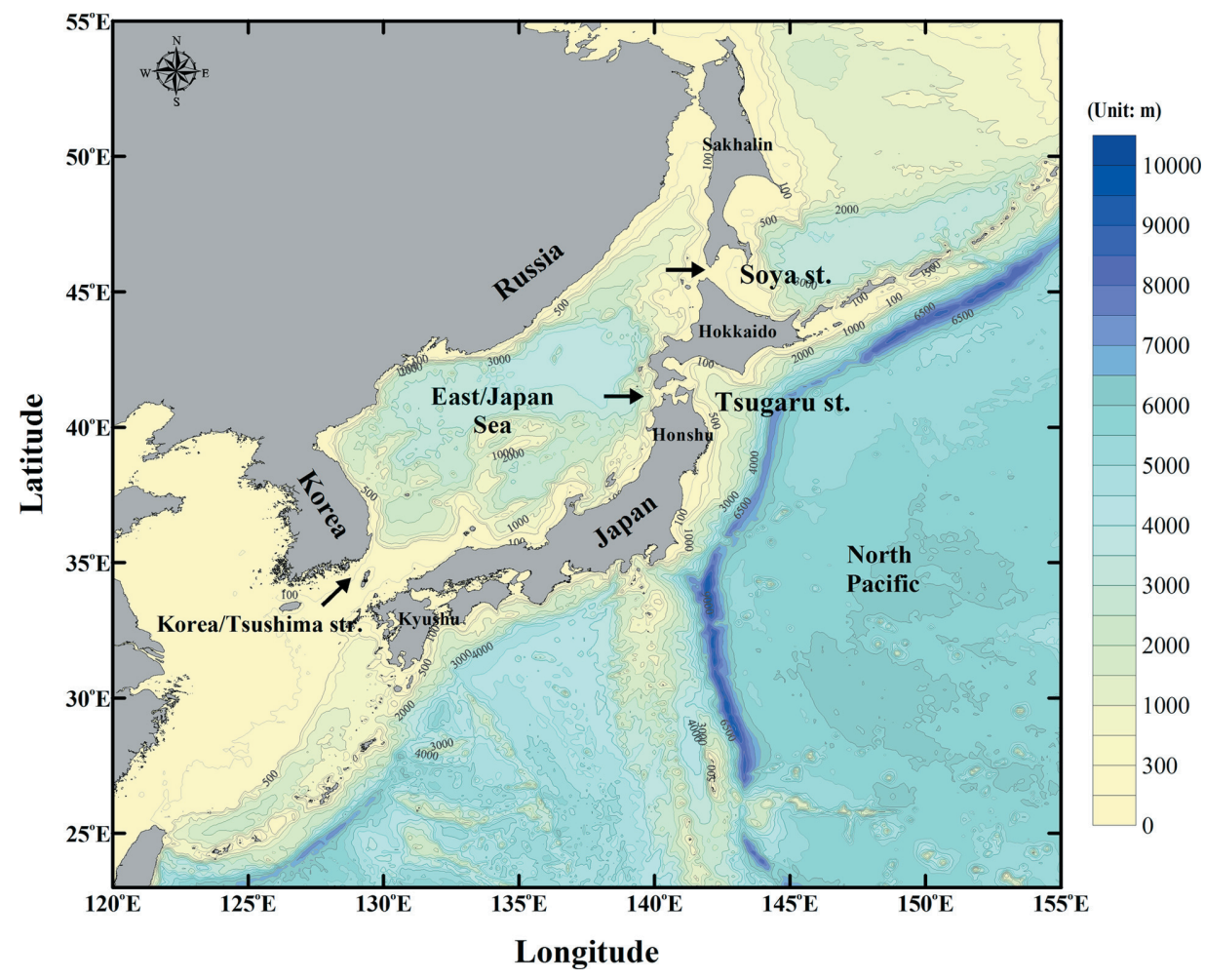

Fig. 1. The East Sea with three straits, Korea/Tsushima, Tsugaru and Soya Straits, and two islands, Honshu/Kyushu and Hokkaido. There are volume transports (arrows) through the three straits. Depths are in meters

approximately 10 sverdrups, much larger than the measured value of about 2.5 sverdrups (Teague et al. 2002; Takikawa et al. 2005; Fukudome et al. 2010). These studies indicate that the non-linear effect is not important in controlling the volume transport through the marginal sea. In addition, the overestimation of volume transport may be induced by the neglect of bottom friction in shallow channels, as mentioned above. Indeed, Seung (2003) succeeded in obtaining a realistic transport of about 2.5 sverdrup by applying the island rule with bottom friction taken into account, in a study where the problem is simplified by considering only a single island.

Up until now, all studies concerning volume transport of the Tsushima Current have been done only for its annual average. Furthermore, The Tsugaru and Soya Straits have been treated as a single channel, i.e., only a single island has been considered. In general, volume transports through these straits are largest in summer-fall and smallest during winter. An interesting thing to remark is that volume transport through the Soya Strait has an annual range of about twice that of the Tsugaru Strait, while the former has annual-mean volume transport of about half that of the latter (Fukamachi et al. 2008; Nishida et al. 2003; Fig. 2). The question in regard to why

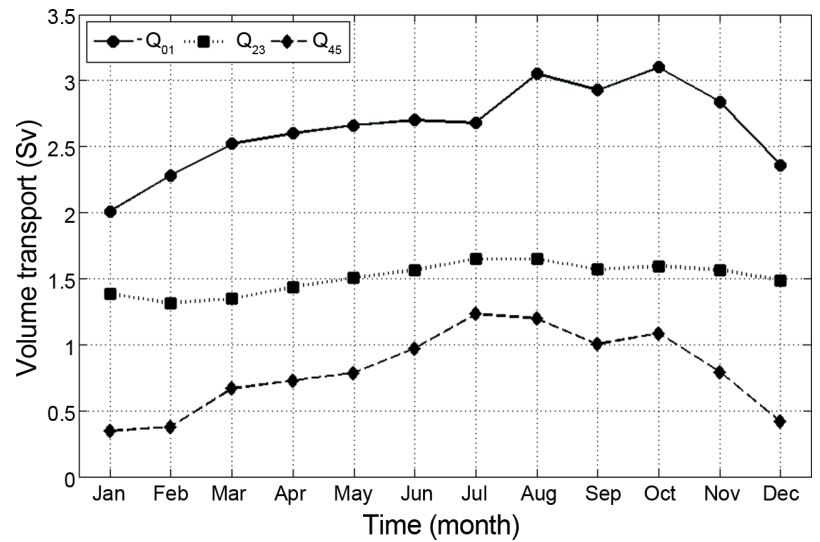

Fig. 2. Monthly variation of volume transports through the Korea/Tsushima $\left(-Q_{01}\right)$, Tsugaru $\left(Q_{23}\right)$ and Soya $\left(Q_{45}\right)$ Straits observed by, respectively, Fukudome et al. (2010), Nishida et al. (2003) and Fukamachi et al. (2008)

there is smaller seasonal variation of volume transport in the Tsugaru Strait than in the Soya Strait remains unanswered. In this paper, we attempt to answer this question by applying the island rule with bottom friction taken into account and using the observed wind data. 


\section{Theory}

Consider a barotropic ocean communicating to the west with a marginal sea through three shallow channels (Fig. 3 ). Take a coordinate system with $x$ - and $y$-axis orienting, respectively, to the east and north with its origin at the southeastern corner of the marginal sea. The three channels are assumed to have the same length $\ell$ extending from $x=-\ell$ to $x=0$. The southernmost strait in $y_{0}(=0)<y<y_{1}$ mimics the Korea/Tsushima Strait, and the other channels in $y_{2}<y<y_{3}$ and $y_{4}<y<y_{5}$, respectively, the Tsugaru and Soya Straits. For convenience, these channels are named $C_{01}, C_{23}$ and $C_{45}$ where the subscript numbers in each channel imply the $y$-positions of the northern and southern ends, for example 0 and 1 in $C_{01}$ mean $y_{0}$ and $y_{1}$ and so on. In the same manner, the island in $y_{1}<y<y_{2}$ and in $y_{3}<y<y_{4}$ are named, respectively, $I_{12}$ and $I_{34}$. The three channels are assumed to be so shallow that the flows there are dominated by bottom friction. Note that in a more simplified problem with a single island, bottom friction has been proved to be an important factor in determining the volume transport (Seung 2003). In the ocean, subtropical and sub-polar gyres are driven by zonal wind. Local wind forcing in the marginal sea is assumed to be negligible. This configuration may idealize the regions around the East Sea basin (Fig. 1).

The equation for the $x$-component of momentum is different from region to region. It is

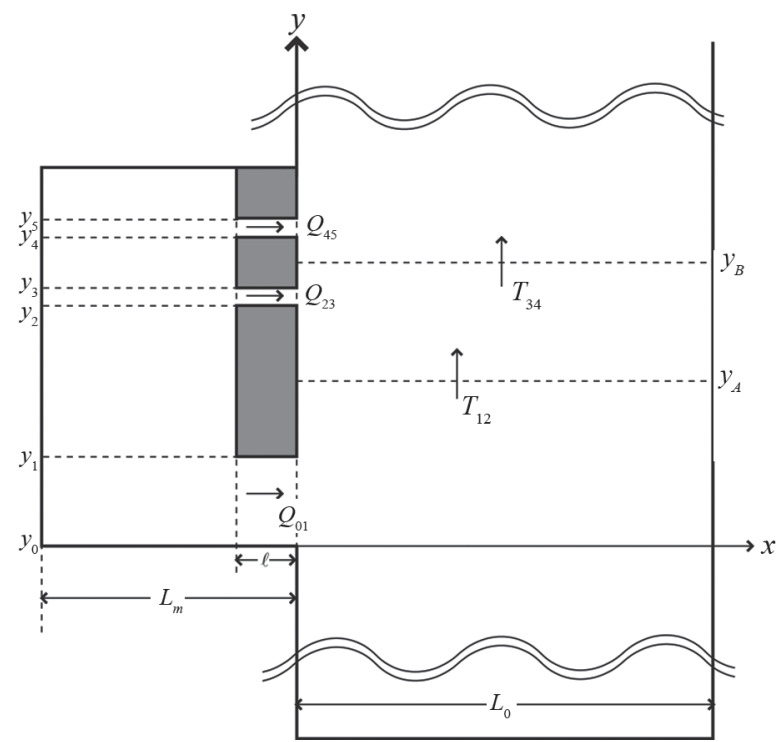

Fig. 3. Idealization of the problem considered. The winddriven ocean $(x>0)$ is connected to the left with a marginal sea $(x<0)$ through three channels. Arrows indicate volume transports

$$
f v-g \frac{\partial \eta}{\partial x}+\frac{\tau}{\rho D}=0
$$

in the ocean, $0<x$, where $f$ is Coriolis parameter, $(u, v)$ are $(x, y)$-components of current velocity, $g$ is gravity constant, $\eta$ is surface elevation measured from the motionless surface, $\tau(y)$ is zonal wind stress varying only with $y, \rho$ is water density and $D$ is bottom depth of the ocean. The wind field is assumed to vary on a much longer time scale than the adjustment time of the flow field such that the latter can be assumed to be in a quasi-steady state. In each channel, the cross-channel component of the current is assumed to be negligible, i.e., $v=0$. In the along-channel direction, the $x$-component of momentum equation is

$$
\frac{r u}{d}+g \frac{\partial \eta}{\partial x}=0
$$

where $d(\ll D)$ is depth and $r$ is the linear bottom friction coefficient in each channel. Elsewhere, the $x$-component of the momentum equation is

$$
f v-g \frac{\partial \eta}{\partial x}=0
$$

The equation for the $y$-component of momentum is

$$
f u+g \frac{\partial \eta}{\partial y}=0
$$

over the whole domain except near the western boundaries of the ocean and marginal sea where friction and nonlinear effect may be important. In (4), the meridional component of wind stress is considered to be unimportant.

Integrating (1) vertically from $z=-D$ to $z=0$ and zonally from $x=0$ to $x=L_{o}$ along the line $y=y_{1}$ leads to

$$
f_{1} T_{12}-g D\left[\eta\left(L_{0}, y_{1}\right)-\eta\left(0, y_{1}\right)\right]+\int_{0}^{L_{0}} \frac{\tau\left(y_{1}\right)}{\rho} d x=0
$$

and the same process along the line $y=y_{2}$ leads to

$$
f_{2} T_{12}-g D\left[\eta\left(L_{0}, y_{2}\right)-\eta\left(0, y_{2}\right)\right]+\int_{0}^{L_{0}} \frac{\tau\left(y_{2}\right)}{\rho} d x=0
$$

where $f_{1}=f\left(y_{1}\right), f_{2}=f\left(y_{2}\right)$ and $T_{12}$ is net meridional volume transport across a latitude line extending from $x=0$ to $x=L_{\mathrm{o}}$ at $y=y_{A}$, with $y_{A}$ lying arbitrarily between $y=y_{1}$ and $y=y_{2}$ (Fig. 3). By subtracting (6) from (5), one obtains

$$
\Delta f_{12} T_{12}=\beta \int_{y_{1}}^{y_{2}} \int_{0}^{L_{0}} T_{s} d x d y+g D\left[\eta\left(0, y_{1}\right)-\eta\left(0, y_{2}\right)\right]
$$

where $\Delta f_{12}=f_{2}-f_{1}$ and $T_{s}=\operatorname{curl} \tau / \rho \beta$ with $\operatorname{curl} \tau=-\partial \tau / \partial y$ 
and $\beta=d f / d y$. In obtaining (7), the circulation theorem is applied to the domain considered, i.e. to the region $0<x<L_{o}$ and $y_{1}<y<y_{2}$. Also used is $\eta\left(L_{o}, y_{1}\right)=\eta\left(L_{o}, y_{2}\right)$, as is evident from the fact that there is no sea level change along the frictionless solid boundary, i.e., by applying $u=0$ to (4). The last term in (7), sea level change along $\left(0, y_{1}\right) \rightarrow\left(0, y_{2}\right)$, is found by line-integrating along the western boundary of which the dynamics is not explicitly known. However, the western boundary can be avoided by taking the line along $\left(0, y_{1}\right) \rightarrow\left(-\ell, y_{1}\right) \rightarrow\left(-\ell, y_{2}\right) \rightarrow\left(0, y_{2}\right)$. As described above, sea level change occurs only along frictional solid boundaries, i.e., along $\left(0, y_{1}\right) \rightarrow\left(-\ell, y_{1}\right)$ and along $\left(-\ell, y_{2}\right) \rightarrow\left(0, y_{2}\right)$. In the frictional channels, downstream sea level change is related with volume transport, as shown in (2). Integrating (2) vertically and zonally along the line $y=y_{1}$ from $x=-\ell$ to $x=0$ leads to

$$
\eta\left(-\ell, y_{1}\right)-\eta\left(0, y_{1}\right)=\frac{R Q_{01}}{g D}
$$

where $R=r D \ell / d^{2} w$, a frictional parameter, $w$ is width of the channel $C_{01}$, and $Q_{01}$ is volume transport through the same channel. Note that, in (8), flow is assumed to be uniform within the channel. In what follows, $\mathrm{R}$ is assumed to be a constant for mathematical simplicity. For reference, $r / d=10^{-5} \mathrm{sec}^{-1}$ is used in Seung (2003). For $\ell / w \sim 1$ and $D / d$ $\sim 10$, then one obtains $R \sim 10^{-4} \mathrm{sec}^{-1}$. In the same manner, integrating (2) vertically and zonally along the line $y=y_{2}$ from $x=-\ell$ to $x=0$ leads to

$$
\eta\left(-\ell, y_{2}\right)-\eta\left(0, y_{2}\right)=\frac{R Q_{23}}{g D}
$$

where $Q_{23}$ is volume transport through the channel $C_{23}$. Note that $\eta\left(-\ell, y_{1}\right)=\eta\left(-\ell, y_{2}\right)$ because there is no friction between the two points $\left(-\ell, y_{1}\right)$ and $\left(-\ell, y_{2}\right)$. Introducing (8) and (9) to (7) leads to

$$
\Delta f_{12} T_{12}=\beta\left(<T_{s}>_{12}\right)+R\left[Q_{23}-Q_{01}\right]
$$

where $\left\langle T_{s}\right\rangle_{12}$ means area integral of $T_{s}$ over the region $0<x<L_{0}, y_{1}<y<y_{2}$. If the same process is repeated for the region $-\ell<x<L_{o}, y_{3}<y<y_{4}$, one obtains

$$
\Delta f_{34} T_{34}=\beta<T_{s}>_{34}+R\left(Q_{45}-Q_{23}\right)
$$

where $\Delta f_{34}=f\left(y_{4}\right)-f\left(y_{3}\right), T_{34}$ is net meridional volume transport across a latitude line extending from $x=0$ to $x=L_{o}$ at $y=y_{B}$, with $y_{B}$ lying arbitrarily between $y=y_{3}$ and $y=y_{4}$ (Fig. 3), $\left\langle T_{s}>_{34}\right.$ means area integral of $T_{s}$ over the region $0<x<L_{0}, y_{3}<y<y_{4}$, and $Q_{45}$ is volume transport through the channel $C_{45}$.

Volume continuity in the region $0<x<L_{o}, y<y_{A}$ leads to

$$
T_{12}=Q_{01}
$$

Volume continuities in the regions $0<x<L_{o}, y_{A}<y$ $<y_{B}$ and $0<x<L_{o}, y_{B}<y$ together with (12) give

$$
\begin{aligned}
& T_{34}=Q_{01}+Q_{23} \\
& Q_{01}+Q_{23}+Q_{45}=0
\end{aligned}
$$

Equation (14) also satisfies the continuity within the marginal sea, $-L_{m}<x<0, y_{0}<y<y_{5}$ (Fig. 3). Expressing $T_{12}, T_{34}$ and $Q_{45}$ in terms of $Q_{01}$ and $Q_{23}$, using respectively, (12), (13) and (14), and introducing them into (10) and (11) lead to

$$
\begin{aligned}
& \left(1+R / \Delta f_{12}\right) Q_{01}-R Q_{23} / \Delta f_{12}={\overline{<T_{s}>}}_{12} \\
& \left(1+R / \Delta f_{34}\right) Q_{01}+\left(1+2 R / \Delta f_{34}\right) Q_{23}={\overline{<T_{s}>}}_{34}
\end{aligned}
$$

where the over-bar denotes the meridional average arising when (10) and (11) are divided by, respectively, $\Delta f_{12}=$ $\beta\left(y_{2}-y_{1}\right)$ and $\Delta f_{34}=\beta\left(y_{4}-y_{3}\right)$. It can be seen that the meridional average of total Sverdrup transport east of an island, the right side of either (15) or (16), referred simply to as "around-island transport", drives volume transport through the channel. Solutions to (15) and (16) are

$$
\begin{aligned}
& Q_{01}=\frac{{\overline{<T_{s}{ }_{12}}}_{1}\left(\Delta f_{12} \Delta f_{34}+2 R \Delta f_{12}\right)+{\overline{<T_{s}>}}_{34} R \Delta f_{34}}{3 R^{2}+2 R\left(\Delta f_{12}+\Delta f_{34}\right)+\Delta f_{12} \Delta f_{34}} \\
& Q_{23}=\frac{-\overline{<T_{s}{ }_{12}}\left(\Delta f_{12} \Delta f_{34}+R \Delta f_{12}\right)+{\overline{\left.<T_{s}\right\rangle_{34}}}_{\left(\Delta f_{12} \Delta f_{34}+R \Delta f_{34}\right)}}{3 R^{2}+2 R\left(\Delta f_{12}+\Delta f_{34}\right)+\Delta f_{12} \Delta f_{34}}
\end{aligned}
$$

From (14), (17) and (18), it is found that

$$
Q_{45}=\frac{-{\overline{<T_{s}{ }_{12}}}_{12} \Delta f_{12}-\overline{\left.<T_{s}\right\rangle_{34}}\left(\Delta f_{12} \Delta f_{34}+2 R \Delta f_{34}\right)}{3 R^{2}+2 R\left(\Delta f_{12}+\Delta f_{34}\right)+\Delta f_{12} \Delta f_{34}}
$$

In the conventional island rule where friction is not considered $(R=0)$, the "around-island transport" east of an island is itself the transport through the channel adjacent to that island, as is evident from (17) through (19) with $R=0$. In the presence of friction $(R \neq 0)$, however, all "around-island transports" interact to one another. For example, if $R=0$ in (17), $Q_{01}$ is the same as

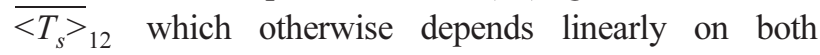


${\overline{\left.<T_{s}\right\rangle_{12}}}_{12}$ and ${\overline{\left.<T_{s}\right\rangle_{34}}}_{\text {for }} R \neq 0$. Overall, it is found that in the presence of friction, the volume transport through a channel is given by a linear combination of all the "around-island transports" created east of the island chain separating the marginal sea and the ocean.

\section{Application of the theory}

In order to apply the theory to the straits of the East Sea, the "around-island transports" should be estimated using the observed wind data. We use here QuikSCAT wind stress data provided by NOAA for the period from November 1999 to October 2009. These data are obtained every week with a spatial resolution of $0.5^{\circ}$ by $0.5^{\circ}$ in longitude and latitude. From these data, monthly values of zonally-integrated wind stress curl are obtained, and shown in a time-latitude diagram (Fig. 4). If divided by $\rho \beta$, these values are equivalent to zonally-integrated Sverdrup transport. It is seen that the zero-stress-curl latitude largely fluctuates east of Hokkaido, extending most northward in the summer and southward in winter. The islands forming the Korea/Tsushima, Tsugaru and Soya Straits are Honshu/Kyushu and Hokkaido (Fig. 1). Hence, the southern tip of Kyushu corresponds to $y_{1}$ in the idealized model; the northern tip of Honshu, the southern tip of Hokkaido, the northern tip of Hokkaido and the southern tip of Sakhalin correspond, respectively, to $y_{2}, y_{3}$, $y_{4}$ and $y_{5}$; Honshu/Kyushu and Hokkaido correspond, respectively, to $I_{12}$ and $I_{34}$; the Korea/Tsushima, Tsugaru and Soya Straits correspond to, respectively, $C_{01}, C_{23}$ and $\mathrm{C}_{45}$ in the model. Accordingly, the "around-island

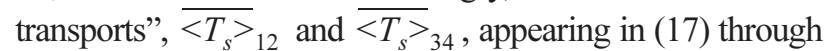
(19) are estimated using the observed wind data (Fig. 5).

The friction coefficient $R$ is unknown, and the relationships (17) through (19) cannot be fully checked. In absence of friction, $R=0$, volume transports through the channels (or straits) are of the same order of magnitude as "around-island transports", as indicated by (17) through (19). The former is in the order of one sverdrup and the latter is an order larger (compare Fig. 2 with Fig. 5). This fact suggests that in the island rule, volume transport may largely be reduced by friction, represented here by $\mathrm{R}$, as has already been shown for a more simplified case (Seung 2003). Hence, $R$ can be assumed to be much larger than $\Delta f_{12}$ or $\Delta f_{34}$ in (17) through (19). If this is the case, and with $\Delta f_{12} \fallingdotseq 2.5 \Delta f_{34}$ (c.f., Fig. 1), (17) through (19) can be approximated to

$$
\begin{aligned}
& Q_{01} \approx\left(\Delta f_{12} / 3 R\right)\left[2{\overline{<T_{s}{ }_{12}}}+0.4{\overline{<T_{s}}}_{34}\right]=\alpha P_{01} \\
& Q_{23} \approx\left(\Delta f_{12} / 3 R\right)\left[-{\overline{<T_{s}>_{12}}}+0.4{\overline{<T_{s}>_{34}}}=\alpha P_{23}\right. \\
& Q_{45} \approx-\left(\Delta f_{12} / 3 R\right)\left[{\overline{<T_{s}>}}_{12}+0.8{\overline{<T_{s}>}}_{34}\right]=\alpha P_{45}
\end{aligned}
$$

where $Q$ 's and $\alpha P^{\prime}$ 's are, respectively, measured and

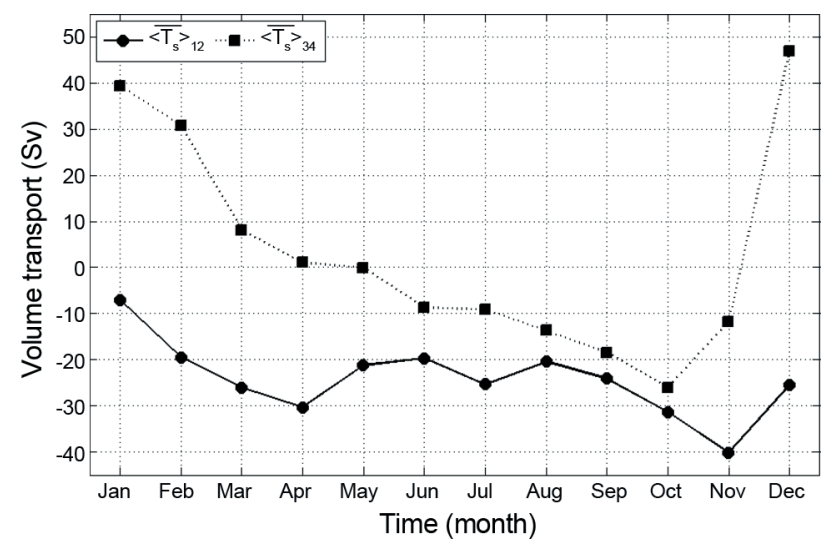

Fig. 5. Monthly variation of "around-island transports" created east of Honshu/Kyushu $\left(\overline{\left\langle T_{s}\right\rangle_{12}}\right)$ and Hokkaido $\left({\overline{<T_{s}>}}_{34}\right)$

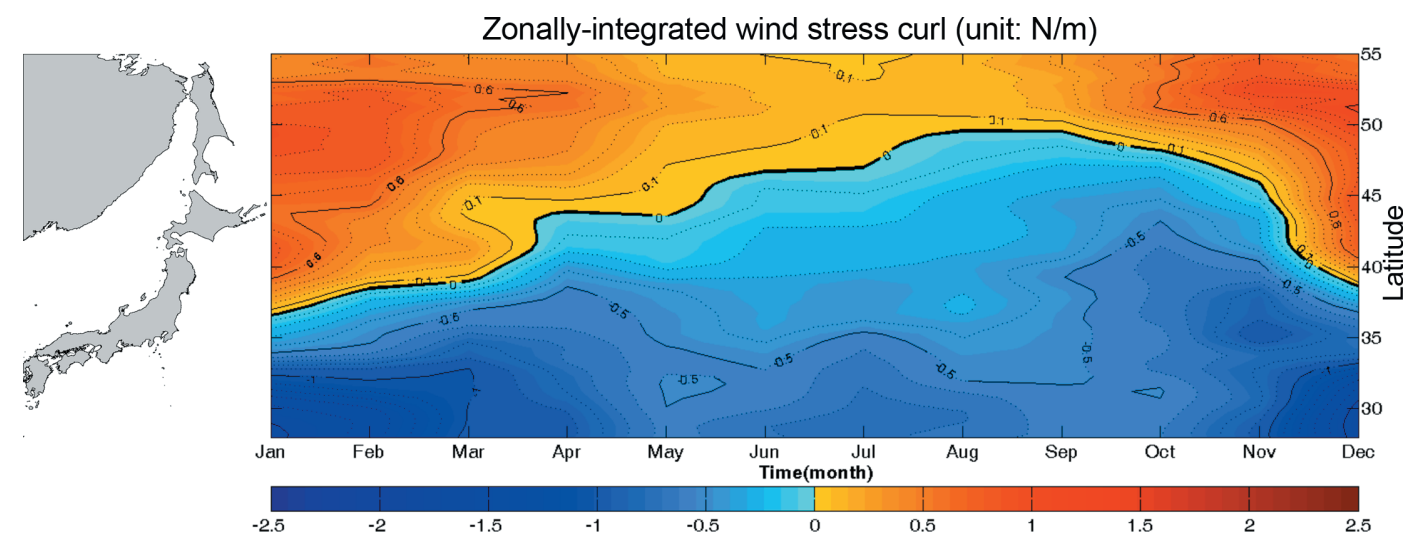

Fig. 4. Time (month)-latitude diagram of zonally-integrated wind stress curl east of Japanese Islands 

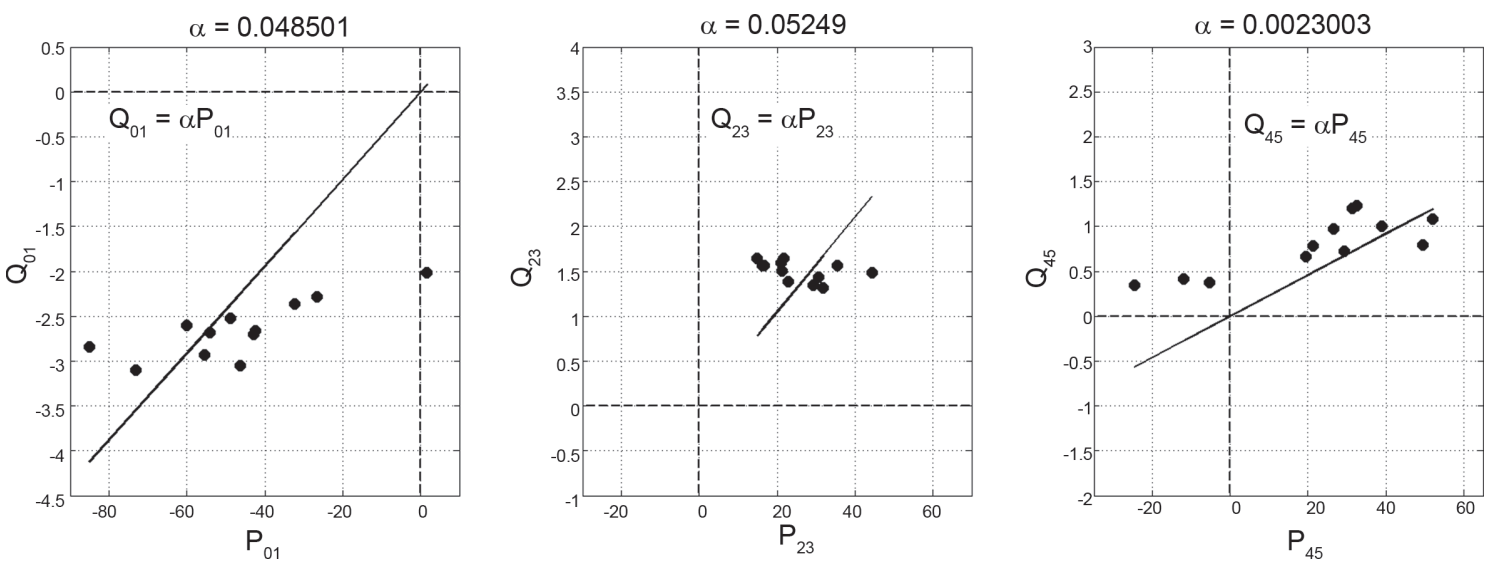

Fig. 6. Statistical estimation of $\alpha=\Delta f_{12} / 3 R$ obtained for each pair of data set $\left(P_{01}, Q_{01}\right),\left(P_{23}, Q_{23}\right)$ and $\left(P_{45}, Q_{45}\right)$. In each pair, $P$ and $Q$ are related with each other by, respectively, (20) through (22)

predicted transports. The unknown constant $\alpha=\Delta f_{12} / 3 R$ can be determined statistically by fitting the right side, $\alpha P$, to the left side, $Q$, in each of (20) through (22), where the former is obtained using the wind data and the latter is measured transport. The three values of $\alpha$ so determined are different one from another probably because of errors in data, both of the volume transport and wind stress curl, and idealization of the problem (Fig. 6). However, all three $\alpha$ turn out to be much smaller than unity, justifying the approximation of (17) through (19) to (20) through (22). Most observations of volume transport have been done in the Korea/Tsushima Strait than in other straits, and there $\alpha$ is found to be 0.0485 according to (20). Hence, $\alpha=0.05$ may be taken as a reasonable one. For $\mathrm{R} \sim 10^{-4} \mathrm{sec}^{-1}$ given earlier and $\Delta f_{12} \sim 2 \times 10^{-5} \mathrm{sec}^{-1}$, one obtains $\alpha \sim 6.7 \times 10^{-2}$ which is quite comparable with $\alpha=0.05$ obtained above statistically.

However, the volume transports predicted by the island rule for $\alpha=0.05$ do not seem to be very accurate because they fluctuate largely around the measured transports (Fig. 7 through 9). The errors in predicted transports may be caused in part by the erroneous wind data used in estimating the "around-island transport". They may also be due to the uncertainty associated with the frictional parameter $R$. In fact, $R$ should be largely different between summer and winter because of the seasonally-changing flow structure. It also may be different from strait to strait because every strait has a different geometrical shape and flow condition. Unfortunately, finding out a more accurate $\mathrm{R}$ is beyond the scope of the present study. Considering the fact that the deviations of predicted transport from the measured one are generally less than 2 sverdrups, the error range of prediction can be taken as 2 sverdrups at most. Then, the seasonal variation of predicted transports

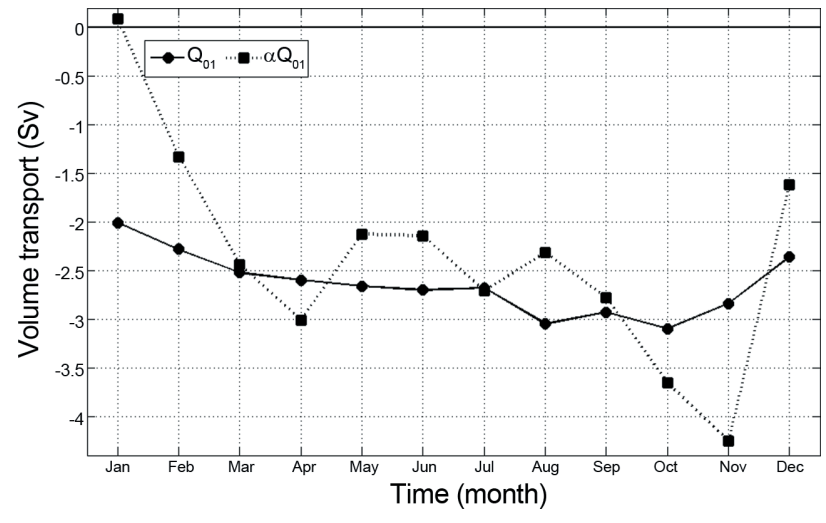

Fig. 7. Monthly variation of volume transports through the Korea/Tsushima Strait predicted by the island rule (20), $\alpha \boldsymbol{P}_{01}$, with $\alpha=\mathbf{0 . 0 5}$, in comparison with those observed, $Q_{01}$

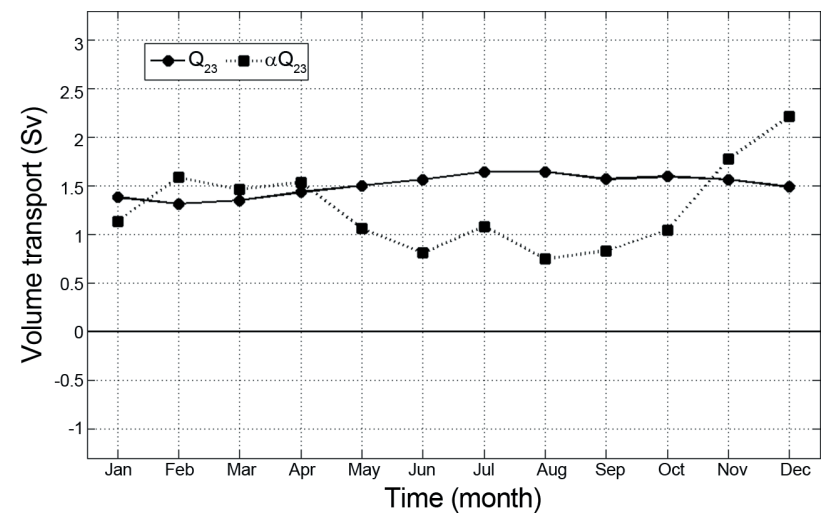

Fig. 8. Monthly variation of volume transports through the Tsugaru Strait predicted by the island rule (21), $\alpha P_{23}$, with $\alpha=0.05$, in comparison with those observed, $Q_{23}$

in the Tsugaru Strait turns out to be insignificant. In both the Korea/Tsushima and Tsugaru Straits, the ranges of 


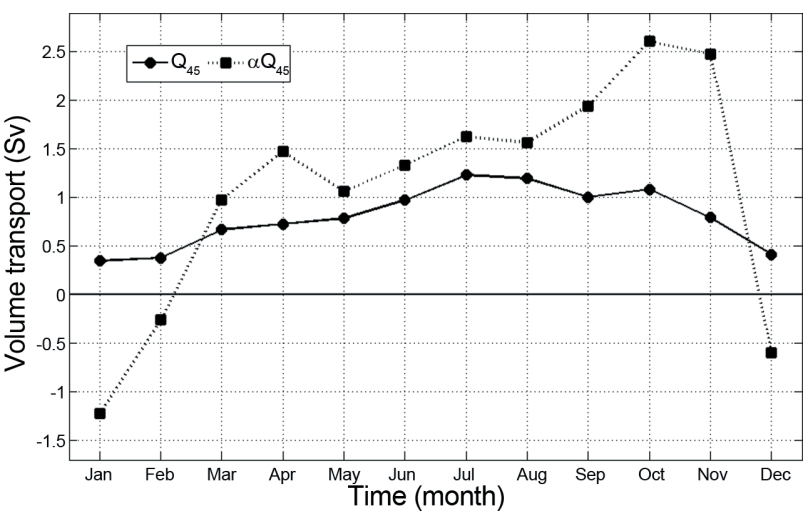

Fig. 9. Monthly variation of volume transports through the Soya Strait predicted by the island rule (22), $\alpha P_{45}$, with $\alpha=0.05$, in comparison with those observed, $Q_{45}$

seasonal variation are about 4 sverdrups, larger than the error range of 2 sverdrups. If we consider only the difference of transports between January and August, it is about 2.5 sverdrups in the Korea/Tsushima Strait and slightly larger than 2.5 sverdrups in the Soya Strait, which are also larger than the error range of 2 sverdrups. Hence, it may be said that the larger seasonal variation in the Korea/Tsushima and Soya Straits compared to the Tsugaru Strait is also confirmed in the predicted transports.

The main question is why the seasonal variation of volume transport through the Tsugaru Strait is smaller than that through the Soya Strait. The physical explanation can be found in (20) through (22). Let $Q_{01}=Q_{01,12}+Q_{01,34}$, $Q_{23}=Q_{23,12}+Q_{23,34}$ and $Q_{45}=Q_{45,12}+Q_{45,34}$ in (20) through (22) where $Q_{01,12}$ is the component of $Q_{01}$ contributed by $\overline{\left\langle T_{s}\right\rangle_{12}}, Q_{01,34}$ is the component of $Q_{01}$ contributed by ${\overline{\left\langle T_{s}\right\rangle_{34}}}$ and so on. In the summertime, the negative ${\overline{\left\langle T_{s}\right\rangle_{12}}}_{12}$ with a large magnitude creates a strong clockwise circulation around Honshu/Kyushu and hence large magnitude of $Q_{01,12}(<0)$ in the Korea/Tsushima Strait. In the same period, negative ${\overline{\left\langle T_{s}\right.}}_{34}$ creates a clockwise circulation around Hokkaido that extends to the Korea/ Tsushima Strait by the effect of bottom friction in the Tsugaru Strait, resulting in $Q_{01,34}(<0)$ in the same direction as $Q_{01,12}$. Hence, large $-Q_{01,12}$ becomes further larger by the effect of $Q_{01,34}$, resulting in largest $-Q_{01}$ during summer (Fig. 10). In the wintertime, the same clockwise circulation is created around Honshu/Kyushu by $\overline{\left\langle T_{s}\right\rangle}$, , but with smaller magnitude. In the same period, positive $\overline{\left\langle T_{s}\right\rangle_{34}}$ creates an anti-clockwise circulation around Hokkaido that extends to the Korea/Tsushima Strait by the effect of bottom friction in the Tsugaru Strait, resulting in $Q_{01,34}$ $(>0)$ in the opposite direction to $Q_{01,12}$. Hence, small $-Q_{01,12}$

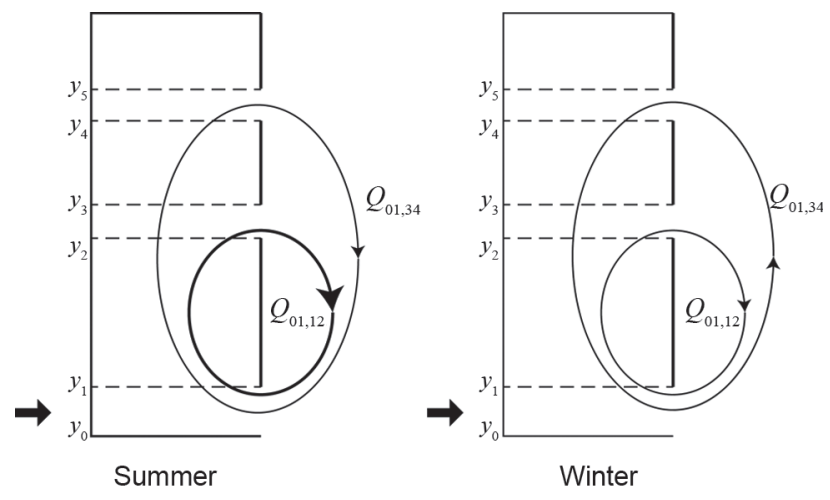

Korea/Tsushima Strait

Fig. 10. Schematic diagram showing the formation of volume transport through the Korea/Tsushima Strait, $Q_{01}$, in summer and winter by the contribution of two components, $Q_{01,12}$ and $Q_{01,34}$,

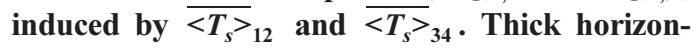
tal arrows indicate location of the Korea/Tsushima Strait. Circular lines with arrows show the two components with thicker lines implying larger transports
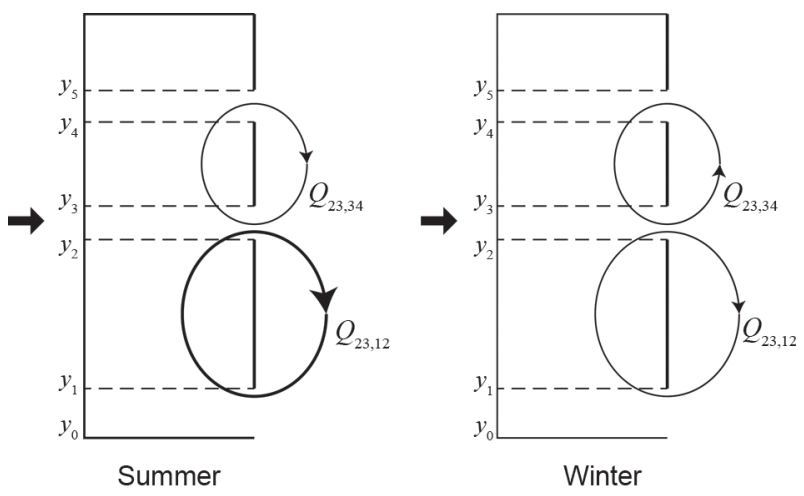

Tsugaru Strait

Fig. 11. Same as Fig. 10 except for volume transport through the Tsugaru Strait, $Q_{23}$

becomes further smaller by the effect of $Q_{01,34}$, resulting in smallest $-Q_{01}$ during winter (Fig. 10). For the Tsugaru and Soya Straits, explanations can be given in the same manner. During summer, the strong clockwise circulation around Honshu/Kyushu associated with negative $\overline{\left\langle T_{s}\right\rangle_{12}}$ creates large $Q_{23,12}(>0)$ in the Tsugaru Strait (Fig. 11). A part of this circulation that extends to the Soya Strait by the effect of bottom friction in the Tsugaru Strait also creates large $Q_{45,12}(>0)$ in the Soya Strait (Fig. 12). Meanwhile, the clockwise circulation around Hokkaido associated with negative $\overline{\left\langle T_{s}\right\rangle}{ }_{34}$ creates $Q_{23,34}(<0)$ in the Tsugaru Strait and $Q_{45,34}(>0)$ in the Soya Strait, hence 

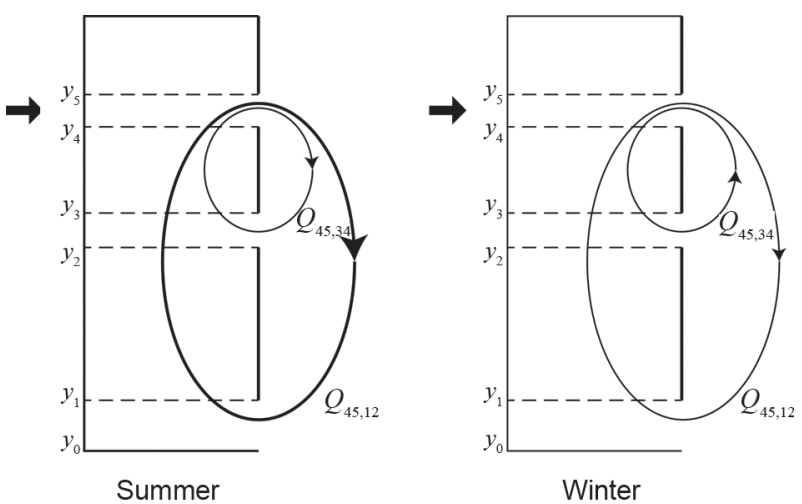

Soya Strait

Fig. 12. Same as Fig. 10 except for volume transport through the Soya Strait, $Q_{45}$

making the large $Q_{23,12}$ smaller in the Tsugaru Strait and making the large $Q_{45,12}$ further larger in the Soya Strait (Fig. 11 and 12). During winter, the weaker clockwise circulation around Honshu/Kyushu associated with negative $\overline{\left\langle T_{s}>\right.}{ }_{12}$ creates $Q_{23,12}(>0)$ of smaller magnitude in the Tsugaru Strait (Fig. 11). A part of this circulation that extends to the Soya Strait by the effect of bottom friction in the Tsugaru Strait also creates small $Q_{45,12}(>0)$ in the Soya Strait (Fig. 12). Meanwhile, the anti-clockwise circulation around Hokkaido associated with positive $\overline{<T_{s}>}{ }_{34}$ creates $Q_{23,34}(>0)$ in the Tsugaru Strait and $Q_{45,34}$ $(<0)$ in the Soya Strait, hence making the small $Q_{23,12}$ larger in the Tsugaru Strait and making the small $Q_{45,12}$ further smaller in the Soya Strait (Fig. 11 and 12). As a result, the seasonal variation of volume transport through the Tsugaru Strait becomes smaller than that through the Soya Strait. Overall, the observed seasonality, larger seasonal variation of volume transport in the Soya Strait than in the Tsugaru Strait, arises essentially from the fact that the "around-island transport" created east of Hokkaido, represented by $\overline{\left\langle T_{s}>\right.}{ }_{34}$, changes its sign from negative during summer to positive during winter, the latter fact being associated with a large seasonal fluctuation of zerostress curl latitude east of Hokkaido.

\section{Concluding remarks}

Among many problems concerning volume transport of the Tsushima Current, a question that has long been unanswered is why the seasonal variation of volume transport is larger in the Soya and Korea/Tsushima Straits than in the Tsugaru Strait. An attempt is made to answer this question in terms of the island rule theory with friction being taken into account. The East Sea is idealized as a marginal sea communicating with a winddriven ocean through three shallow channels separated by two islands extending in the meridional direction. The three channels mimic, respectively, the Korea/Tsushima, Tsugaru and Soya Straits. Both the ocean and marginal sea are assumed to be barotropic and flows in the channels are assumed to be largely controlled by bottom friction. The model results indicate that volume transport through a channel is determined not only by the circulation created around the adjacent island but also by those created around the neighboring islands farther away. The latter fact is due to the presence of bottom friction in the channels. The model is applied to the Korea/Tsushima, Tsugaru and Soya Straits using observed wind data. The result successfully demonstrates the general trend of observed seasonality although the model-predicted values look somewhat erroneous. The model indicates that the otherwise maximum (minimum) transport in summer (winter) created by the "around-island transport" east of Honshu/Kyushu are hindered (enhanced) in the Tsugaru Strait and enhanced (hindered) in the Soya Strait by the "around-island transport" east of Hokkaido, resulting in larger seasonal variation of volume transport in the Soya Strait than in the Tsugaru Strait. Hence, the observed seasonality arises essentially from the fact that the "around-island transport" created east of Hokkaido changes its sign from negative in the summertime to positive in the wintertime, the latter fact being associated with a large seasonal fluctuation of zero-stress curl latitude east of Hokkaido. Although the model explains the general pattern of the observed seasonal variation of volume transport, the model-predicted transports are not satisfactory in accuracy. In this regard, the most critical fact may be that the frictional parameter is assumed to be a constant which otherwise varies in space and time. It is also possible that volume transport is affected by local forcing such as the passage of tropical cyclones (Moon et al. 2009) and sea level changes around the East/Japan Sea (Tsujino et al. 2008). Overall, this paper only suggests the island rule as a candidate mechanism that can explain the seasonal variation of the volume transports through the Korea/Tsushima, Tsugaru and Soya Straits.

\section{Acknowledgements}

This study is supported by Inha University. 


\section{References}

Bleck R, Smith LT (1990) A wind-driven isopycnic coordinate model of the north and equatorial Atlantic Ocean 1. Model development and supporting experiments. J Phys Oceanogr 95:3273-3285

Fang G, Zhao B, Zhu Y (1991) Water volume transport through the Taiwan strait and the continent shelf of the East China Sea measured with current meters. In: Takano K (ed), Oceanography of Asian Marginal Seas, Elsevier, New York, pp 345-358

Fukamachi Y, Tanaka I, Ohshima KI, Ebuchi N, Mizuta G, Yoshida H, Takayanagi S, Wakatsuchi M (2008) Volume transport of the Soya Warm Current revealed by bottommounted ADCP and ocean-radar measurement. J Oceanogr 64:385-392

Fukudome K, Yoon JH, Ostrovskii A, Takikawa T (2010) Seasonal volume transport variation in the Tsushima Warm Current through the Tsushima Straits from 10 years of ADCP observations. J Oceanogr 66:539-551

Godfrey JS (1989) A Sverdrup model of the depth-integrated flow for the world ocean allowing for island circulations. Geophys Astro Fluid 45:89-112

Katoh O, Teshima K, Abe O, Fujita H, Miyaji K, Morinaga K, Nakagawa N (1996) Process of the Tsushima Current formation revealed by ADCP measurements in summer. J Oceanogr 52:491-507

Lie HJ, Cho CH (1994) On the origin of the Tsushima Warm Current. J Geophys Res 99:25081-25091

Minato S, Kimura R (1980) Volume transport of the western boundary current penetrating into a marginal sea. J Oceanogr Soc Japan 36:185-195

Moon JH, Hirose N, Yoon JH, Pang IC (2009) Effect of the along-strait wind on the volume transport through the
Tsushima/Korea Strait in September. J Oceanogr 65:1729

Nishida Y, Kanomata I, Tanaka I, Sato S, Takahashi S (2003) Seasonal and interannual variations of the volume transport through the Tsugaru Strait. Umi no Kenkyu 12:487-499

Nof D (1993) The penetration of Kuroshio water into the Sea of Japan. J Phys Oceanogr 23:797-807

Nof D (2000) Why much of the Atlantic circulation enters the Caribbean Sea and very little of the Pacific circulation enters the Sea of Japan. Prog Oceanogr 45:39-67

Ohshima KI (1994) The flow system in the Japan Sea caused by a sea level difference through shallow straits. J Geophys Res 99:9925-9940

Seung YH (2003) Significance of shallow bottom friction in the dynamics of the Tsushima Current. J Oceanogr 59: $113-118$

Takikawa T, Yoon JH, Cho KD (2005) The Tsushima Warm Current through Tsushima Straits estimated from Ferryboat ADCP data. J Phys Oceanogr 35:1154-1168

Teague WJ, Jacobs GA, Hwang PA, Book JW, Perkins HT (2002) Low-frequency current observations in the Korea/ Tsushima strait. J Phys Oceanogr 32:621-1641

Toba Y, Tomizawa K, Kurasawa Y, Hanawa K (1982) Seasonal and year-to-year variability of the TsushimaTsugaru Warm Current system with its possible cause. La mer 20:41-51

Tsujino H, Nakano H, Motoi T (2008) Mechanism of currents through the straits of the Japan Sea: Mean state and seasonal variation. J Oceanogr 64:141-161

Received Oct. 9, 2012

Revised Nov. 15, 2012

Accepted Nov. 22, 2012 